\title{
4.1.4 HYDROPHOBIC AND OLEOPHOBIC COATINGS
}

\author{
S. Pilotek, H. Schmidt
}

\section{INTRODUCTION}

The formation of a solid-liquid interface between a liquid drop and a solid surface is called wetting. The extent of which wetting occurs is in most cases accurately described by the Young-equation (1).

$$
\gamma_{\mathrm{s}}=\gamma_{\mathrm{sl}}+\gamma_{1} \cos \theta
$$

where $\gamma_{\mathrm{s}}$ is the solid-atmosphere interfacial tension, $\gamma_{1}$ is the liquid-atmosphere interfacial tension, $\gamma_{\mathrm{sl}}$ is the solid-liquid interfacial tension, and $\theta$ is the contact angle. Three aspects of this equation should be held in mind:

1. Wetting can be expressed and quantified by the contact angle $\theta$. A surface is completely wetted, if $\theta=0^{\circ}$ (film formation), and there is no wetting at all, if $\theta=180^{\circ}$. If $\theta$ is high, the shape of a droplet is spherical, leading to a reduced contact area between the liquid and the surface.

2. Wetting depends on 3 phases: the solid surface, the liquid and the atmosphere.

3. The central parameter of the Young equation is the surface tension $\gamma$, an interface property related to the energy dU necessary to increase the surface of the substance $(\gamma=\mathrm{dU} / \mathrm{d} \sigma)$. In principle, the free energy of the surface is readily calculated by determination of the surface tension $\gamma_{\mathrm{s}}$. Whereas contact angles are meaningful only in a given context of surface, liquid and atmosphere, the free surface energy allows a more general characterization of a surface.

The Young equation (1) ("sessile drop situation") does not apply if liquid drops move on (tilted) solid surfaces. Here, dynamic contact angles should be used. In this case, the contact angles at the front $\left(\theta_{\text {adv(ancing) }}\right)$ and at the rear $\left(\theta_{\text {rec(eding) }}\right)$ of the drop are usually unequal. A small difference between the $\theta$ 's (hysteresis) results in an easy sliding of liquid droplets. The sliding angle (tilt angle of the substrate at which a liquid drop starts to move down the plane) may be used to quantify the dynamic wetting behavior [2]. Smooth hydrophobic surfaces have typically a hysteresis and sliding angle of 20 to $30^{\circ}$.

Materials with low free surface energy are antiadhesive because (1) the contact area of a liquid on the surface is reduced (high contact angle) and (2) the 
chemical interaction is low. Therefore, the force per contact area necessary to remove a contamination is low. A helpful estimation is given by the critical surface tension $\gamma_{c}$, an empirical quantity defined by the intercept of the plot of $\cos \theta$ vs. $\gamma_{1}$ for $\cos \theta=1$ measured for a homologous series of nonpolar liquids (Zisman-plot) [2]. In general, liquids with $\gamma_{1}<\gamma_{c}$ wet the surface, in contrast to liquids with $\gamma_{1}>\gamma_{\mathrm{c}}$.

The surface free energy of polyolefins is in the order of $32 \mathrm{~mJ} \cdot \mathrm{m}^{-2}$ and the contact angle for water is $60^{\circ}$ to $80^{\circ}$. Such surfaces repel water $\left(\gamma_{1}=72 \mathrm{mN} \cdot \mathrm{m}^{-1}\right)$, but not oily liquids $\left(\gamma_{1} \approx 30 \mathrm{mN} \cdot \mathrm{m}^{-1}\right)$. The surface free energy of PTFE or other polyfluorinated polymers is considerably lower (ca. $20 \mathrm{~mJ} \cdot \mathrm{m}^{-2}$ ) with a contact angle up to $110^{\circ}$ against water. The surface free energy of silicate glass is high, about $70 \mathrm{~mJ} \cdot \mathrm{m}^{-2}$ and the contact angle vs. water is in the order of $40^{\circ}$. It is wetted by almost any liquid and is therefore easily soiled and laborious to clean. Therefore, antiadhesive, low-free surface energy coatings are very attractive, especially for the automotive, architectural and display industry.

\section{HYDROPHOBIC COATINGS ON GLASS}

Academic research on the preparation and characterization of hydrophobic coatings on glass is rare and most methods are described in the patent literature, stressing their importance for industry. Three different approaches exist: a) simple molecular systems, b) sol-gel matrices doped with organic fluoropolymers, and c) organic-inorganic sol-gel nanocomposites.

a) Molecular systems consist of a solution of an organically substituted silane with reactive $\mathrm{Si}-\mathrm{X}$ bonds (X: e.g. $\mathrm{Cl}$, OAlkyl). These are cleaved by the surface $\mathrm{Si}-\mathrm{OH}$ groups, generating stable Si-O-Si bonds and volatile HX. This approach has been reviewed however without focus for glass substrates [3]. Aprotic solvents such as (chlorinated) alkanes, or mixtures of them are employed [4-6]. Coating compositions that contain a hydrolyzed fluoroalkyl silane in alcohol solution are rarely employed [7] as their shelf-life is limited. The obtained surface energy depends greatly on the organic substituent: alkyl usually leads to surface free energies comparable to those of polyolefins (ca. $32 \mathrm{~mJ} \cdot \mathrm{m}^{-2}$ ) [8]. Accordingly modified substrates are hydrophobic but not oleophobic. Hydrophobic and oleophobic surfaces with energies of ca. $20 \mathrm{~mJ} \cdot \mathrm{m}^{-2}$ can be obtained by using silanes with polyfluoroalkyl substituents $[9,10]$. Such films are industrially manufactured and employed in automotive applications [11]. Surfaces with a sliding angle of only 10 to $15^{\circ}$ against water can be realized. The contact angle vs. water remains above $100^{\circ}$ even after $1000 \mathrm{~h}$ weathering or 5000 cycles abrasion with a flannel cloth $\left(0.3 \mathrm{~kg} / \mathrm{cm}^{2}\right)$. The effective film thickness is in the order of one molecule, so a specific advantage of such formulations is the possibility to produce ultrathin coatings [12] but coating homogeneity is difficult to achieve and the presence of coating defects may lead to a higher surface free energy. 
b) The second approach comprises organic polyfluoropolymers imbedded in a sol-gel matrix [13] deposited by wet chemical processes and then thermally cured. A high amount of organic polymer increases the time-stability against boiling water and attack by high $\mathrm{pH}$ values solutions but soften the coatings so that mechanical stability is not a specific advantage of these hybrid materials [14, 15]. The organic polymers are introduced for instance as PTFE particles, polyfluoro-co-polymers or perfluoroethers with hydroxyl end groups [16]. To ensure transparency, the mixed phases should be finely dispersed at the nanometer or even molecular scale. Also, attention is needed to abide this dispersive state. For that purpose a specially silyl-modified organic co-polymer has been developed to enhance the binding of the polymer to the sol-gel matrix [17].

c) The third approach uses sol-gel formulations of fluoroalkylsilanes in combination with other silanes to obtain co-condensates [18]. These materials are called ORMOCER ${ }^{\circledR}$ ("organically modified ceramics") or CERAMER ("ceramic polymer") $[19,20]$. The solvents are mostly alcohols, but some water-based systems have been described [21, 22]. In these nanocomposites, the organic and the inorganic network are covalently bound and homogeneously intermingled at the nanometer-scale, so that the coatings present enhanced mechanical stability. Patents claim a sol prepared from tetraethoxysilane (TEOS), (perfluorooctyl)ethyltrialkoxysilane (FOS) and water for improved abrasion resistance of the obtained hydrophobic coatings [23, 24]. This composition has been investigated in detail in $[25,26]$. Contact angles as high as $118^{\circ}$ against water and surface free energies below $10 \mathrm{~mJ} \cdot \mathrm{m}^{-2}$ are reported for $80 \mu \mathrm{m}$ thick coatings [26] containing only $2 \mathrm{~mol} \%$ fluorosilane (FOS). This was explained by an accumulation of fluoroalkyl groups at the surface. The surface free energy of the coating is not affected by a subsequent thermal treatment at $250^{\circ} \mathrm{C}$ for $1 \mathrm{~h}$. Firing at $\mathrm{T}>300^{\circ} \mathrm{C}$ leads to a loss of the fluoroalkyl groups, the surface free energy is drastically increased and the contact angle decreases considerably down to $70^{\circ}$. An enhanced linkage of the FOS improving the thermal stability was however achieved by an additional ammonia-treatment after a thermal curing at $300{ }^{\circ} \mathrm{C}$ for $30 \mathrm{~min}$. The initial contact angle of $110^{\circ}$ against water is kept after tempering for $250 \mathrm{~h}$ at $300{ }^{\circ} \mathrm{C}$.

The major advantage of this approach lies in its high versatility. Various silanols or their precursors can be used in the sol-gel synthesis to tailor the material properties such as surface free energy, color, hardness, abrasion resistance, mechanical or chemical stability [19, 20, 27-29]. The shelf-life or weatherability is for instance increased by using aminogroup- or methacrylgroup-substituted silanes apart from fluoroalkylsilanes and TEOS as starting materials [21, 30]. The use of nanoparticles together with suitable silane precursors, solvents and additives allows to obtain NANOMERs ${ }^{\circledR}$ ("nano-polymers") materials with many different additional properties [31]. The homogeneous incorporation of nanoparticles enhances the densification and improves the mechanical scratch resistance and chemical durability of the nanocomposites and may confer additional features such as anti-microbial or UV protection functions [19, 32]. Due to the nanometer size of the particles, the coatings maintain a high transparency 
between 400 and $1000 \mathrm{~nm}$. Hydrophobic and oleophobic properties comparable to that of PTFE $\left(20 \mathrm{~mJ} \cdot \mathrm{m}^{-2}\right)$ can be obtained by using fluoroalkyl-substituted alkoxysilanes such as FOS or (perfluorohexyl)ethyltriethoxysilane (FHS) [33-36] (contact angles $>100^{\circ}$ for water and $>45^{\circ}$ for hexadecane). The materials have a pronounced gradient structure, with a high concentration of fluoroalkyl groups at the coating - air interface so that only a small amount $(1.7 \mathrm{~mol} \%)$ of fluoroalkyl silane is necessary to obtain an effective repellency [34, 35, 37]. Also, this accounts for an excellent adhesion of the coatings on various substrates such as glass, metals and polymers [40]. The gradient is due to the accumulation of surface-active fluorosilanol molecules and -condensates at the interface [38]. Therefore, the atmosphere needs to be controlled carefully during application and curing. If the fluorosilane concentration is above the critical micelle concentration (CMC), the fluoroalkylsilanol micelles are homogeneously distributed within the coating [39]. The inner structure of the coating is fixed during the curing process, usually performed by thermal treatment. The thermal stability of Nanomers can be increased by about $100{ }^{\circ} \mathrm{C}$ compared to conventional Ormocers, but the temperature should be kept below $400{ }^{\circ} \mathrm{C}$ to prevent thermal degradation of the organic components. Nanomers can also be tailored by curing at a lower temperature or even by UV light [19]. These possibilities are especially interesting for tempered glass.

A benefit of antiadhesive sol-gel coatings lies in the "easy-to-clean" effect [41]. Antiadhesive coatings soiled by different mixtures such as flue ash and graphite (1wt.-\%), or water, oil and pyrogenic silica are easily cleaned even by using low-impact cleaning procedures like showering (rain model). Good abrasion resistance and weatherability are also important properties to be satisfied for outdoor applications [21, 30, 41]. Nanomer coatings with a low content of organic substituents show no yellowing after $30 \mathrm{~d}$ of UV irradiation and the adhesion as well as the contact angle are maintained in wet climate and under weatherometer conditions. Very low haze values (2-4\%) are obtained after 100 abrasion Taber test cycles [20, 33, 35].

\section{SUPERHYDROPHOBIC COATINGS ON GLASS}

Apart from the chemical constitution, wetting is also influenced by the chemical homogeneity and the morphology of surfaces. Rough hydrophobic surfaces called "superhydrophobic", "ultrahydrophobic", or "Lotus effect" surfaces [42] have found increasing academic and industrial interest, because of their drastic increase of the contact angles and the disappearance of the hysteresis effect. As the Young equation (1) is only valid for ideal smooth, homogeneous surfaces, a more sophisticated approach is necessary to describe rough substrates.

The equation of Cassie and Baxter describes the behavior of a liquid drop which rests on two different mediums at the same time (e.g. a textile) by defining a macroscopically observable contact angle $\theta_{\text {obs. }}$ If one of them is a gas, the equation reduces to: 


$$
\cos \theta_{\text {obs }}=\mathrm{Q}_{1} \cos \theta_{0}-\mathrm{Q}_{2}
$$

where $\mathrm{Q}_{1}$ is the fraction area of the liquid drop in contact with the solid, $\mathrm{Q}_{2}$ is the remaining fraction area of the drop in contact with the atmosphere $\left(\theta=180^{\circ}\right)$, and $\theta_{0}$ is given by the Young equation (1).

The same idea can be applied to extremely porous or rough hydrophobic substrates, where air is enclosed between liquid and substrate.

Typical superhydrophobic surfaces have a roughness $>5 \mu \mathrm{m}$ [43]. They scatter the light, are generally opaque, and are unsuitable for glass, where transparency is demanded. The roughness of such coatings can be however controlled down to values lower than $100 \mathrm{~nm}$, too small to scatter the visible light [44]. Unfortunately, information about scattering effects (haze value) of superhydrophobic films is scarcely available.

Transparent superhydrophobic surfaces can be realized by depositing a thin hydrophobic coating (see above) on a suitably patterned substrate [45] obtained for instance by dip coating a sol prepared from aluminum-sec-butoxide, ethylacetoacetate and water in iso-propanol. After firing at $400{ }^{\circ} \mathrm{C}$ and immersion into boiling water the alumina coating turns transparent, but highly porous [46]. The 20 to $50 \mathrm{~nm}$ roughness can be controlled by varying the immersion time, leading to a transparency of up to $92 \%$. After hydrophobizing the structure with a fluoroalkyl silane solution, the static contact angle against water is as high as $165^{\circ}$. In another approach the patterning was accomplished by spin-coating a suspension of boehmite particles and aluminum acetylacetonate onto a glass substrate with subsequent firing at $500{ }^{\circ} \mathrm{C}$ [47]. The structure is believed to evolve because of the sublimation of the aluminum acetylacetonate. The transparency of the film is $>90 \%$, but pronounced Rayleigh scattering is observed at small wavelengths. Doping with $2 \% \mathrm{TiO}_{2}$ (using titanium acetylacetonate) leads to improved UV resistance of the coating. A contact angle $>140^{\circ} v s$. water remained even after $800 \mathrm{~h} \mathrm{UV}$ illumination and after $1800 \mathrm{~h}$ of outdoor exposure $[48,49]$.

A suitable structure was also obtained by a phase-separation technique [49]. The addition of $1 \mathrm{wt} .-\%$ of an acrylic polymer to a TEOS sol leads to a turbid, phase-separated emulsion. Spin-coating onto Pyrex glass and firing at $500{ }^{\circ} \mathrm{C}$ for 30 min results in rough transparent films with a high hardness (1-2 GPa). Presumingly, the acrylic polymer is thermally decomposed in the firing step, leaving 100 to $1000 \mathrm{~nm}$ crevices in the silica film. The structure was hydrophobized by a fluoroalkylsilane solution and shows a contact angle against water of $151^{\circ}$ and a transmittance of $>90 \%$ at $500 \mathrm{~nm}$.

A one-step approach for superhydrophobic coatings has been developed by adding suitable pyrogenic silica nanoparticles (Aerosil) to a TEOS/FHS sol system $[50,51]$. A rough structure evolves without additional patterning during the spin-coating process. A static contact angle vs. water of $150^{\circ}$ and a hysteresis of $<1^{\circ}$ was obtained. A transparency of $>95 \%$ transmission $(400-800 \mathrm{~nm})$ and a haze value of only $2 \%$ was achieved [52]. The mechanical stability of the coating is however poor. 
184 Sol-gel technologies for glass producers and users

\section{CONCLUSION}

The sol-gel technology is a versatile tool for the preparation of hydrophobic and oleophobic coatings on glass. Smooth organic-inorganic nanocomposites coatings have been developed to an elaborate state with tailor-made properties. Apart from excellent repellency due to the low surface free energy, the materials are robust and applicable by conventional wet-coating techniques. Moreover, the sol-gel technology offers interesting possibilities in the development of superhydrophobic coatings, but considerable development is still necessary to reach technical application.

\section{REFERENCES}

1. D. Myers, Surfaces, Interfaces, and Colloids - Principles and Applications, VCH, Weinheim 1991

2. R. E. Johnson, R. H. Dettre, Wettability and Contact angles, in: Surface and Colloid Science Vol. 2, E. Matijevic (ed.) Wiley, New York, 85 (1969)

3. M. J. Owen, D. E. Williams, Surface modification by fluoroalkyl-functional silanes: A review, J. Adhesion Sci. Technol., 5, 307 (1991)

4. K. Ogawa, N. Mino, M. Soga, Transparent substrate with monomolecular film thereon and method of manufacturing the same, EP 492545 B1 (1992)

5. J. Gun, Composition for producing a monomolecular film on the surfaces of various mate, CA 2022039 AA (1992)

6. M.J. Azzopardi, L. Dellatre, X. Talpaert, Substrat a propriétés hydrophiles ou hydrophobes améliorées, comportant des irrégularités, FR 2756276 B1 (1998)

7. M. Asai, K. Kamitani, M. Kawazu, H. Yamamoto, Coating solution and method for waterrepellent treatment and kit for preparing such solution, EP 1097979 A1 (2001)

8. Mitsubishi Chemical Corp., Composition for forming coating silica film, JP 08120225 A (1996)

9. Matsushita Electrical Industries Co. Ltd., Water Repellent/Oil Repellent Glass, JP 08169729 A (1996)

10. Asahi Glass, Treating agent for surface of glass, JP 58223634 A2 (1983)

11. T. Morimoto, Y. Sanada, H. Tomonaga, Wet chemical functional coatings for automotive glasses and cathode ray tubes, Thin Solid Films, 392, 214 (2001)

12. B.P. Singh, R. Subramaniam, Thin films, EP 607146 B1 (1999)

13. H. Kobayashi, A. Masatomi, Dispersion improver for fluororesin powder and organic resin composition, JP 2000080232 A2 (2000)

14. H. Matsuo, M. Yamauchi, N. Matsunaga, Fluorine-containing polymer composition for coating and use thereof, JP 03195757 A2 (1991)

15. S. Endo, I. Sugiyama, T. Moriwaki, Coating composition, JP 02029449 A2 (1990)

16. L. Mascia, T. Tang, Ceramers based on crosslinked epoxy resin-silica hybrids: low surface energy systems, J. Sol-Gel Sci. Techn. 1998, 13, 405

17. S. Homma, S. Murakami, T. Izumi, Solvent soluble fluorine-containing polymer, coating composition containing the same and coating process thereof, EP 185526 B1 (1991)

18. H. Schmidt, Thin Films, the Chemical Processing up to Gelation, in: Structure and Bonding, vol. 77, R. Reisfeld, C.K. Jørgensen (eds.), Springer, Berlin (1992)

19. H. Schmidt, Application of Ormocers, in: Sol-Gel Sci. Techn., E. J. Pope (ed.), , ACERS, 253 (1995)

20. K.-H. Haas, S. Amberg, K. Rose, Functionalized coating materials based on inorganic-organic polymers, Thin Solid Films, 351, 198 (1999)

21. M. Asai, S. Ichinohe, K. Matsumura, Water-soluble surface treating agents, EP 738771 B1 (2001) 
22. E. Arpac, H. Schirra, H. Schmidt, Nanostrukturierte Formkörper und Schichten und deren Herstellung über stabile wasserlösliche Vorstufen, DE 19816136 A1 (1998)

23. T. Itoh, S. Shiiki, K. Takada, T. Teranishi, K. Tojima, H. Yamamoto, Method for forming waterrepellant film, EP 678344 A2 (1995)

24. A. Azuma, A. Nishihara, Water-and oil-repellent transparent coating material, JP 07173412 A1 (1995)

25. T. Nakagawa, M. Soga, A new method for fabricating water repellent silica films having high heat-resistance using the Sol-Gel method, J. Non-Crystalline Solids, 260, 167 (1999)

26. H-J. Jeong, D-K. Kim, S-B. Lee, S-H. Kwon, K. Kadono, Preparation of Water-Repellent Glass by Sol-Gel Process Using Perfluoroalkylsilane and Tetraethoxysilane, J. Coll. Interface Sci., 235, $130(2001)$

27. J. Kron, G. Schottner, K.-J. Deichmann, Glass design via hybrid Sol-Gel materials, Thin Solid Films, 392, 236 (2001)

28. T. Honda, J. Kaetsu, Anti-fogging coating composition, JP 05125299 A1 (1993)

29. A. Carre, Treatment of articles to impart non-stick and water repellent properties thereto, EP 565743 B1 (1992)

30. Showa Denko KK, Acrylic-functional methyfluoroalkylsilsesquioxane compound, JP 05086193 A (1993)

31. H. Schmidt, R. Kasemann, Beschichtungszusammensetzungen auf der Basis von fluorhaltigen anorganischen Polykondensaten, deren Herstellung und deren Verwendung, WO 1992021729 (1992)

32. P. Bier, P. Capellen, H. Krug, S. Sepeur, S. Stein, Coating Compositions Containing Cerium Dioxide, WO 2000037577 (2000)

33. H. Schmidt, Synthesis of Organically modified glasses by Sol-Gel techniques, Bol. Soc. Esp. Ceram. Vid., 31C, 185 (1992)

34. R. Kasemann, H. Schmidt, Coatings for Mechanical and Chemical protection based on OrganicInorganic Sol-Gel Nanocomposites, 1st Europ. Workshop on Hybrid Organic-Inorganic Materials, Bierville/France (1993)

35. R. Kasemann, S. Brück, H. Schmidt, Fluorine modification of ORMOCER (ORganically MOdified CERamics)-coating Materials, Eurogel 91 (Proc. 2nd Europ. Conf. Sol-Gel Techn.), Saarbrücken (1991)

36. R. Kasemann, S. Brück, H. Schmidt, Schmutzabweisende, transparente Beschichtungen auf Basis fluromodifizierter anorganisch-organischer Nanokomposite, 66. Glastech. Tagung, Fulda (1992)

37. H. Schmidt, Heteropolysiloxanes by Sol-Gel Techniques: Composite Materials with Interesting Properties, Organosilicon Chemistry II: From molecules to materials, N. Auner, J. Weis (eds.), VCH Weinheim, 737 (1996)

38. H. Schmidt, Inorganic-Organic Composites by Sol-Gel Techniques, J. Sol-Gel Sci. Tech., 1, 217 (1994)

39. S. Pilotek, INM, unpublished results

40. S. Schmitz-Stöwe, S. Brück, H. Schmidt, Low Surface Free Energy Nano-Composite-Materials as Anti Graffiti Coatings, European Coating Conference on Antigraffiti Coatings, Berlin (1999)

41. T. Benthien, R. Kasemann, INM, unpublished results

42. Review: A. Nakajima, K. Hashimoto, T. Watanabe, Recent Studies on Super-Hydrophobic Films, Monatshefte Chem., 132, 31 (2001)

43. W. Barthlott, DE 4426962 (1994); W. Barthlott, C. Neinhuis, Purity of the sacred Lotus, or escape from contamination in biological surfaces, Planta, 202, 1 (1997)

44. C.F. Bohren, D.R. Huffman, Absorption and Scattering of Light by Small Particles, Wiley, New York (1983)

45. Matsushita Elect. Industries Co Ltd., Exceedingly water-repellent film and its production, JP 06025449 A, (1994)

46. K. Ogawa, M. Soga, Y. Takada, I. Nakayama, Development of a Transparent and Ultrahydrophobic Glass Plate, Jpn. J. Appl. Phys., 32, L614 (1993);

47. K. Tadanaga, N. Katata, T. Minami, Super-Water-Repellent $\mathrm{Al}_{2} \mathrm{O}_{3}$ Coating Films with High Transparency, J. Am. Ceram. Soc., 80, 1040 (1997); K. Tadanaga, N. Katata, T. Minami, Formation Process of Super-Water-Repellent $\mathrm{Al}_{2} \mathrm{O}_{3}$ Coating Films with High Transparency by the SolGel Method, J. Am. Ceram. Soc., 80, 3213 (1997); 
186 Sol-gel technologies for glass producers and users

T. Minami, N. Katata, K. Tadanaga, Preparation and characterization of super-water-repellent $\mathrm{Al}_{2} \mathrm{O}_{3}$ coating films with high transparency, SPIE, 3136, 168 (1997)

48. A. Nakajima, A. Fujishima, K. Hashimoto, T. Watanabe, Preparation of Transparent Superhydrophobic Boehmite and Silica Films by Sublimation of Aluminum Acetylacetonate, Adv. Mater., 11, 1365 (1999)

49. A. Nakajima, K. Hashimoto, T. Watanabe, K. Takai, G. Yamauchi, A. Fujishima, Transparent Superhydrophobic Thin Films with Self-Cleaning Properties, Langmuir, 16, 7044 (2000)

50. A. Nakajima, M. Miwa, K. Abe, K. Hashimoto, T. Watanabe, Transparent super-hydrophobic coatings on Glass, in: Proceedings 3rd International Conference on Coatings on Glass (ICCG), H.A. Meinema, C.I.M.A. Spee, M.A. Aegerter (eds.), Maastricht/Netherlands, 253 (2000)

51. P. Müller, S. Pilotek, H. Schmidt, Wettability of microstructured, hydrophobic Sol-Gel coatings, poster presented at the sol-gel workshop, Padova 2001

52. S. Pilotek, H. Schmidt, Wettability of microstructured, hydrophobic Sol-Gel coatings, J. Sol-Gel Sci. Tech., 26, 789 (2003)

53. P. Müller, S. Pilotek, H. Schmidt, Hydrophobe und Oleophobe Beschichtungen über Sol-Gel Materialien und Nanokomposite, HVG Kolloquium „Beschichtung und Oberflächenveredelung von Glas" Frankfurt/Main 13.11.2001 